\title{
Rotavirus infection activates the UPR but modulates its activity
}

Jose Luis Zambrano', Khalil Ettayebi', Walid S Maaty², Nicholas R Faunce1, Brian Bothner ${ }^{2}$ and Michele E Hardy ${ }^{*}$

\begin{abstract}
Background: Rotaviruses are known to modulate the innate antiviral defense response driven by IFN. The purpose of this study was to identify changes in the cellular proteome in response to rotavirus infection in the context of the IFN response. We also sought to identify proteins outside the IFN induction and signaling pathway that were modulated by rotavirus infection.

Methods: 2D-DIGE and image analysis were used to identify cellular proteins that changed in levels of expression in response to rotavirus infection, IFN treatment, or IFN treatment prior to infection. Immunofluorescence microscopy was used to determine the subcellular localization of proteins associated with the unfolded protein response (UPR).

Results: The data show changes in the levels of multiple proteins associated with cellular stress in infected cells, including levels of ER chaperones GRP78 and GRP94. Further investigations showed that GRP78, GRP94 and other proteins with roles in the ER-initiated UPR including PERK, CHOP and GADD34, were localized to viroplasms in infected cells.

Conclusions: Together the results suggest rotavirus infection activates the UPR, but modulates its effects by sequestering sensor, transcription factor, and effector proteins in viroplasms. The data consequently also suggest that viroplasms may directly or indirectly play a fundamental role in regulating signaling pathways associated with cellular defense responses.
\end{abstract}

\section{Background}

Rotavirus infections cause life-threatening gastroenteritis in infants and young children, resulting in considerable morbidity and mortality worldwide. Repeated exposure to infectious virus ultimately results in a protective immune response, as reflected by two efficacious vaccines licensed for use in multiple countries [1]. Rotaviruses are members of the family Reoviridae and contain a segmented double-stranded RNA genome encapsidated by a triple-layered protein shell. The genome encodes six structural proteins (VP1-VP6) and six nonstructural proteins (NSP 1-NSP6). Virus replication is completely cytoplasmic, and replication and doublelayered particle assembly occurs in perinuclear inclusions called viroplasms [2-4]. Viral dsRNA replication is carried out within these inclusions, and structural

\footnotetext{
* Correspondence: mhardy@montana.edu

'Immunology and Infectious Diseases, Montana State University, Bozeman MT, 59718, USA

Full list of author information is available at the end of the article
}

proteins VP1, VP2, VP3 and VP6 accumulate to form the double-layered capsid (DLP). The mechanism of viroplasm assembly is unknown, however NSP2 and NSP5 are required for formation as well as for the recruitment of viral proteins [2,3,5-7]. Assembly of triple-layered particles occurs through binding of double-layered particles to NSP4, which is an ER transmembrane receptor for budding particles [8,9]. As particles bud through the ER they acquire VP7, VP4 and a transient envelope that is removed prior to release from cells by a $\mathrm{Ca}^{2+}$-dependent mechanism that is not completely understood $[10,11]$. Virus then is released from the cell by incompletely defined mechanisms that may include release by non-classical vesicular transport [12] and/or virus release upon cell death by cell lysis.

The global cell response to rotavirus infection manifested by changes in gene expression has been studied primarily at the transcript level. Cuadras et al reported the first comprehensive analysis of the transcriptional response to rotavirus infection in $\mathrm{CaCo-2}$ cells [13].
Ciomed Central

(c) 2011 Zambrano et al; licensee BioMed Central Ltd. This is an Open Access article distributed under the terms of the Creative Commons Attribution License (http://creativecommons.org/licenses/by/2.0), which permits unrestricted use, distribution, and reproduction in any medium, provided the original work is properly cited. 
Changes in transcript abundance were related to genes associated with multiple cellular processes including proteins associated with cell structure, stress, transcription regulators, calcium regulators and the IFN response. Other narrower investigations reported expression of cytokine and chemokine profiles in rotavirus infected cells or cells treated with virus-like particles [14-16]. The first studies on changes in gene expression in rotavirus infected cells at the protein level were performed by Taylor et al [17] using 2D gel electrophoresis and MS/MS. This study identified two chaperone proteins, GRP78 (also known as $\mathrm{BiP}$ ) and GRP94 that were up-regulated at the level of both mRNA and protein. GRP78 and GRP94 are ER resident chaperones that assist in protein folding and were subsequently shown to play roles in rotavirus morphogenesis $[17,18]$. GRP78 also functions in regulation of the ER sensors of cell stress, as described later. The purpose of this study was to identify changes in the cellular proteome in response to rotavirus infection, particularly those that occur in the context of the IFN response. The Type I IFN response to rotavirus infection is receiving increased attention following identification of the viral IFN antagonist NSP1. NSP1 functions in targeted proteasome-dependent degradation of interferon regulatory factors 3,5 and 7 , and F-box protein $\beta$-TrCP, the result of which at minimum, is down-regulation of expression of IFN and IFN-regulated genes [19-23]. Additional mechanisms of IFN antagonism are evident in the prevention of nuclear translocation of the p65 subunit of NF $\kappa \mathrm{B}$, and STAT1 and STAT2 $[21,24]$. How rotavirus infection may modulate other cell signaling pathways that also function in host defense is not known.

Several proteins were identified as differentially regulated by OSU infection, IFN treatment or both, including the ER chaperones GRP78 and GRP94. Interestingly, most of the proteins modulated by OSU showed decreased levels, and many of these were associated with cellular stress responses. These identifications led us to further analyze proteins associated with cell stress, specifically the unfolded protein response (UPR). The primary function of the UPR is to restore cell homeostasis under conditions of ER stress brought on by accumulation of unfolded or misfolded proteins $[25,26]$. The data presented here show the UPR is activated in rotavirus infected cells, but then likely is down-regulated due to redistribution of ER chaperones, sensors and effector proteins to viroplasms. Together the results suggest viroplasms may play a lead role in the manipulation of cellular processes, in addition to its known function in rotavirus morphogenesis.

\section{Methods}

\section{Cells and virus}

MA104 monkey kidney cells were maintained in M199 media (Mediatech) supplemented with $5 \%$ fetal bovine serum (FBS, Atlanta Biologicals). Virus stocks of rhesus rotavirus RRV and OSU were prepared and titered as previously described [20]. For infections, virus was treated with $10 \mu \mathrm{g} / \mathrm{ml}$ of TPCK-trypsin for 30 minutes at $37^{\circ} \mathrm{C}$ and then inoculated onto MA104 cell monolayers at the desired multiplicity of infection.

\section{Infections and IFN treatments}

2D-Differential Gel Electrophoresis (DIGE) experiments were performed with OSU. MA104 cells were cultured to confluence in $1210 \mathrm{~cm}$ culture plates. Six of the plates were treated with $10 \mathrm{ml}$ of serum free M199 containing $400 \mathrm{U} / \mathrm{ml}$ of IFN $\alpha$ (R\&D Systems). The remaining six plates were treated with serum-free M199 without IFN. The plates were incubated for 18 hours at $37^{\circ} \mathrm{C}$. After $18 \mathrm{hrs}$, three plates from each treatment group were infected with OSU at a multiplicity of three $\mathrm{pfu} / \mathrm{cell}$ in fresh media with or without IFN. The remaining three plates in each treatment group were mock treated with the original contents (serum free M199, or serum-free M199 containing $400 \mathrm{U} / \mathrm{ml}$ of IFN). All plates were incubated for six hours at $37^{\circ} \mathrm{C}$. The experimental outline resulted in four treatment groups with three biological replicates in each group: 1 ) mock infected, no IFN; 2) mock infected, IFN treated; 3 ) infected, no IFN; and 4) infected, IFN treated.

Cells were harvested and washed three times with 10 $\mathrm{ml}$ of calcium/magnesium-free PBS (PBS-cmf) containing $1.0 \mathrm{mM} \mathrm{NaVO}$. Cells were collected by centrifugation for 10 minutes at $500 \times g$. After the final wash, the supernatant was discarded and the pellets were suspended in $300 \mu \mathrm{l}$ of 2-D gel sample buffer ( $30 \mathrm{mM}$ Tris$\mathrm{HCl} \mathrm{pH} \mathrm{8.5,} 7 \mathrm{M}$ urea, $2 \mathrm{M}$ thiourea, 4\% CHAPS, $1 \%$ ASB-14, $50 \mathrm{mM}$ DTT, 0.002\% bromophenol blue and protease inhibitor cocktail) and transferred to a $2.0 \mathrm{ml}$ microcentrifuge tube. Acetone-precipitated proteins were collected by centrifugation for 30 minutes at $16,000 \times g$ at $0^{\circ} \mathrm{C}$. Pellets were suspended in $500 \mu \mathrm{l}$ of 2D sample buffer and protein concentration was determined with the RcDc Protein Assay system (BioRad).

\section{CyDye Labeling}

Proteins in each sample were labeled with CyDyes (GE Amersham) following the specifications of the manufacturer. The $\mathrm{pH}$ of the samples was adjusted to 8.5 by addition of 2D sample buffer containing $30 \mathrm{mM}$ Tris, $\mathrm{pH} 8.5$, and protein concentrations were determined by RcDc assay. CyDyes were reconstituted in DMF (Sigma: St. Louis, MO) according to the manufacturer's protocol. $50 \mu \mathrm{g}$ of protein from each biological replicate in each treatment group were labeled with $400 \mathrm{pmol}$ of CyDyes and incubated for 10 minutes on ice in the dark. The labeling reaction was stopped by the addition of $1.0 \mu \mathrm{l}$ of $10 \mathrm{mM}$ lysine, followed by a ten minute incubation on ice in the dark. Groups 1 and 3 were 
labeled with Cy3, and groups 2 and 4 were labeled with Cy5. $25 \mu \mathrm{g}$ of protein from each of the 12 samples were pooled and batch labeled with 2400 pmol of Cy2 as the internal standard. Groups 1 and 2 were multiplexed on the same gels, and groups 3 and 4 were multiplexed on the same gels. $50 \mu \mathrm{g}$ of the Cy2 labeled samples were added to each gel as the internal standard.

\section{D electrophoresis}

$24 \mathrm{~cm}$ IPG strips (pH 5.3-6.5 or pH 3-5.6, GE Amersham) were actively rehydrated for 20 hours at 50 volts in a Protean IEF cell (BioRad). Narrow range pH strips were used to increase the resolution. The rehydrated strips then were transferred to an IPGphor (GE Amersham) and proteins were focused at $20^{\circ} \mathrm{C}$. Strips were equilibrated for 15 minutes in SDS equilibration buffer (50 mM tris- $\mathrm{HCl} \mathrm{pH} \mathrm{8.8,} 6 \mathrm{M}$ urea, $30 \mathrm{v} / \mathrm{v}$ glycerol, $2 \%$ w/v SDS, and $.002 \%$ bromophenol blue) containing 65 mM DTT. The strips then were transferred to fresh SDS equilibration buffer containing $135 \mathrm{mM}$ iodoacetamide and incubated for an additional 15 minutes. Second dimension separation was done in a DALT2 separation unit on a SDS-12\% polyacrylamide gel sealed with $0.5 \%$ agarose.

\section{Image Analysis}

Analytical gels were scanned at a resolution of 100 microns using the Typhoon imaging system (GE Amersham). Scanned images were analyzed with the Progenesis SameSpots software package (Nonlinear Dynamics). Spots were determined to be differentially up- or downregulated based on both an ANOVA analysis and power determination between the normalized volumes of the spots from the averaged gel images for the four treatment groups. The threshold of significance was set to ANOVA $\mathrm{p}<0.05$ and a power value $>0.8$. Spots that met both these statistical criteria were considered differentially regulated.

\section{Preparative gels, trypsin digestion and mass spectrophotometric (MS) analysis}

Preparative gels were loaded with $500 \mu \mathrm{g}$ to $1.0 \mathrm{mg}$ of unlabeled protein in 2D focusing buffer $(7 \mathrm{M}$ urea, $2 \mathrm{M}$ thiourea, $2 \%$ CHAPS, $1.5 \% \mathrm{pH} 5.5-6.7$ or $\mathrm{pH} 3.5-5.0$ IPG buffer, $5 \mathrm{mM}$ of fresh DTT, .002\% bromophenol blue) in a final volume of $450 \mu$ l. The spots corresponding to those on the gel images from the Progenesis analysis were excised with a pipette tip, destained in $50 \%$ acetonitrile $(\mathrm{ACN})$ in $50 \mathrm{mM} \mathrm{NH} \mathrm{HCO}_{3}$ and then dehydrated in a speedvac. Gel pieces were rehydrated in 100 $\mu \mathrm{l}$ of $1.5 \mathrm{mg} / \mathrm{ml} \mathrm{DTT}$ in $25 \mathrm{mM} \mathrm{NH} \mathrm{NCO}_{3}$ for one hour at $56^{\circ} \mathrm{C}$. The DTT solution was removed and replaced with $100 \mu \mathrm{l}$ of $10 \mathrm{mg} / \mathrm{ml}$ iodoacetamide in 25 $\mathrm{mM} \mathrm{NH} \mathrm{HCO}_{3}$. The tubes were gently shaken for 45 minutes on a vortex mixer at room temperature. The liquid was discarded and the gel pieces were washed with $100 \mu \mathrm{l}$ of $100 \mathrm{mM} \mathrm{NH} \mathrm{HCO}_{3}$ with gentle shaking for 10 minutes at room temperature, washed twice more with $50 \% \mathrm{ACN} / 50 \mathrm{mM} \mathrm{NH}_{4} \mathrm{HCO}_{3}$, and then dehydrated for 15 minutes in a speedvac.

In-gel trypsin digestions for MS were performed as previously described [27]. Peptide fragments were loaded on a nanoC18 trap column and separated on a nanoC19 analytical column. Gradient elution was accomplished over 12 minutes at a flow rate of $0.5 \mu \mathrm{l} / \mathrm{ml}$ using Agilent's ChipCube LC module interfaced to an Agilent XCTUltra nanoESI-IonTrap-MS equipped with collision induced dissociation cell with Helium as the collision gas.

\section{Protein identification and Gene Ontology (GO) analysis}

Peptides were identified by searching the NCBInr database with the Mascot search engine's MS/MS Ion Search (Matrix Science, http://www.matrixscience.com/). Carbamidomethylation was set as a fixed modification. Peptide tolerance was set a $\pm 0.8 \mathrm{Da}$ and MS/MS tolerance to $\pm 0.3 \mathrm{Da}$. Only peptides that were determined to be statistically significant based on Mascot MOWSE score were considered for protein identifications. In the case of VP6 where only a single peptide was found, this peptide was consistently found in replicate runs and the MS/MS data was manually inspected.

GO analysis was performed with the Database for Annotation, Visualization and Integrated Discovery (DAVID; http://david.abcc.ncifcrf.gov/[28]. The entire gene list was subjected to Functional Annotation Clustering Tool with Homo sapiens as the background list. Annotation clusters with enrichment values over 1.8 (where $<1.3$ is considered insignificant) were further considered.

\section{Immunoblots}

Sixty $\mu \mathrm{g}$ of protein were loaded onto a $12 \%$ polyacrylamide gel and then proteins were transferred to nitrocellulose membrane. The membrane was blocked in $10 \%$ non-fat dry milk (BLOTTO) in PBS for 30 minutes, and then incubated with rabbit polyclonal anti-GRP78 antibody (Cell Signaling), followed by secondary HRP-conjugated goat-anti-rabbit antibody (Jackson ImmunoResearch). Proteins were detected with ECL chemiluminescent reagent (Thermo Scientific). Membranes were reprobed with mouse-anti-actin antibody (Abcam) as a loading control.

\section{Immunofluorescence microscopy}

MA104 cells were cultured on coverslips in 24-well plates at a density of $2.5 \times 10^{5}$ cells $/ \mathrm{ml}$. At $48 \mathrm{~h}$ post seeding, cells were mock infected or rotavirus infected 
with OSU or RRV at a MOI of $5 \mathrm{pfu} / \mathrm{cell}$. Seven hours post-infection (hpi) the cells were fixed with $4 \%$ paraformaldehyde (PFA) in PBS for seven minutes at room temperature (RT). Autofluorescent aldehyde groups were blocked with $50 \mathrm{mM}$ ammonium chloride $\left(\mathrm{NH}_{4} \mathrm{Cl}\right)$ in PBS for 15 minutes at RT. Cells were permeabilized with $0.1 \%$ Triton X-100 in PBS for seven minutes, and then incubated with $3 \%$ bovine serum albumin (BSA) for one hour. The cells were labeled with specific antibodies for: GRP94 (Goat, Santa Cruz Biotechnologies), GRP78 (Goat, Santa Cruz Biotechnologies), ATF6 (Rabbit, AbCam), XBP1 (Mouse, Cell Signaling), p-PERK (Rabbit, Santa Cruz Biotechnologies), GADD34 (Goat, AbCam), Nrf2 (Rabbit, Santa Cruz Biotechnologies), and CHOP (Mouse, Cell Signaling). The secondary antibodies used were: Alexa 488 (Mouse-Rabbit Invitrogen), Alexa 594 (Mouse-Rabbit, Invitrogen) and FITC (Goat, Pierce) conjugated. Anti-rotavirus antibodies included anti-NSP1 (Rabbit) and VP6 (Mouse, 4B2D2). Antibodies to cellular proteins produced in rabbits were confirmed to have no reactivity to rotavirus proteins. Samples were mounted and sealed in anti-fade mounting medium ProLong Gold with DAPI (Invitrogen). All samples were observed with the epi-fluorescence microscope Eclipse 80i (Nikon), using an APO series lens $60 \times / 1.40$ (oil immersion) (Nikon). The images were acquired using a monochrome camera DS-Qi1Mc (Nikon) controlled by the Nis-Element software (Nikon, ver. 3.10). Images were edited for brightness and contrast using the ImageJ software (NIH, ver. 10.2).

\section{2-Deoxy-glucose treatment}

2-deoxy-glucose (2DG) was used to activate the UPR according to the protocol established by Gaddameedhi et al [29]. Briefly, MA104 cells were grown on glass coverslips to confluence, and then treated with $10 \mathrm{mM}$ 2DG for 48 hours. Medium was changed to MEM containing 10\% FBS without 2DG fourteen hours prior to mock infection.

\section{RT-PCR}

MA104 cells were infected with RRV or OSU for $7 \mathrm{~h}$ at a MOI of $10 \mathrm{pfu} / \mathrm{cell}$. Total cellular RNA was isolated with modified Trizol extraction (TRI Reagent; Molecular Research Center, Inc; Ohio, USA) and RNeasy column cleanup (RNeasy Mini Kit; Qiagen). RNA integrity was assessed with Agilent 2100 Bioanalyzer and Agilent RNA 6000 Nano Reagents. cDNA was synthesized using $0.5 \mu \mathrm{g}$ RNA in a $20 \mu \mathrm{L}$ reaction mixture using the Quantitect Reverse Transcription Kit (Qiagen) and Mastercycler Personal thermal cycler (Eppendorf). The primers specific to XBP1 (F-5'-AATGAAGTGAGGCCAGTGG-3'; R5'-TCAATACCGCCAGAATCCATG-3') based on sequence accession NM_0050803 were purchased from Integrated DNA Technologies.

\section{Results}

Differentially expressed proteins in OSU infected and IFN treated cells

2D-DIGE is a sensitive and efficient method for screening a significant portion of the proteome for changes in protein expression. To improve the depth of coverage, narrow $\mathrm{pH}$ range isoelectric focusing (IEF) strips were used. Total soluble protein was analyzed using IEF ranges of 3.0-5.6 and 5.6-6.5, generating 495 and 950 protein spots on all replicate gels, respectively. Differential analysis showed that 123 spots were differentially regulated as defined by the statistical criteria outlined in Materials and Methods. Each of the 123 spots was selected for in-gel proteolysis and LCMS analysis, from which 32 unique protein IDs were returned (Figure 1). Nineteen proteins were modulated by OSU infection, with 13 of these showing decreased levels in infected cells compared to mock infected controls. The presence of up-regulated proteins without known internal ribosome entry sequences in their respective mRNAs suggests the observed decreases are not only a result of virus-induced global inhibition of capdependent translation. Additional evidence that translation of cellular mRNA still is occurring during infection is provided by detection of unfolded protein response effectors CHOP and GADD34 (see below).

The levels of 14 proteins were modulated by IFN treatment, and most showed an increase compared to mock treated controls. Fifteen proteins were differentially regulated when cells were treated with IFN prior to infection as compared to mock treated controls. Seven proteins of this group (not including VP6) were modulated by OSU infection alone, and the change in expression level was the same for each condition. That is, if a protein was down-regulated by IFN treatment prior to infection, it also was down-regulated during infection alone. These observations suggest OSU has little to no effect on this group of IFN-modulated proteins, which includes glyceraldehyde-3-phosphate dehydrogenase, proline-4-hydroxylase, erp29, erp57, hrnp H1, septin 2, and mitofilin. Six of the proteins differentially regulated in cells treated with IFN prior to infection also were modulated by IFN treatment alone. Erp29, Tu translation elongation factor (mitochondrial), and eIF4A were up-regulated by IFN treatment alone, but the levels were decreased in cells treated with IFN and then infected with OSU, suggesting virus infection may have a direct effect on expression of these proteins, even in the presence of IFN.

\section{GO analysis and co-regulated proteins}

GO analysis classified proteins into multiple cellular processes and functions including cellular redox activity, regulation of apoptosis, unfolded protein binding, nucleotide binding, protein folding and protein localization. Analysis of each of these categories in the context 


\begin{tabular}{|c|c|c|c|c|c|c|}
\hline Protein Name & $\begin{array}{c}\text { Accession } \\
\text { Number } \\
\text { (UniProt) }\end{array}$ & $\begin{array}{l}\text { Mowse } \\
\text { Score }\end{array}$ & $\begin{array}{c}\text { No. Of } \\
\text { Peptides } \\
(P<0.05)\end{array}$ & $\begin{array}{l}\text { Mock: } \\
\text { IFN- } \alpha\end{array}$ & $\begin{array}{l}\text { Mock: } \\
\text { OSU }\end{array}$ & $\begin{array}{l}\text { Mock: } \\
\text { OSU + } \\
\text { IFN-a }\end{array}$ \\
\hline VP6 (porcine rotavirus) & -- & 164 & 1 & & & \\
\hline lamin $\mathrm{a} / \mathrm{c}$ & P02545 & 143 & 3 & & & \\
\hline ornithine aminotransferase & P04181 & 94 & 3 & & & \\
\hline glyceraldehyde-3-phosphate dehydrogenase & P04406 & 102 & 2 & & & \\
\hline heat shock $27 \mathrm{kDa}$ protein 1 & P04792 & 120 & 2 & & & \\
\hline enolase 1, (alpha) & P06733 & 161 & 6 & & & \\
\hline $\begin{array}{l}\text { procollagen-proline, 2-oxoglutarate 4-dioxygenase (proline 4- } \\
\text { hydroxylase), beta polypeptide }\end{array}$ & P07237 & 156 & 2 & & & \\
\hline heat shock 70 kDa protein 5 (GRP78; Bip) & P11021 & 276 & 2 & & & \\
\hline heat shock protein $90 \mathrm{kDa}$ beta (GRP94), member 1 & P14625 & 406 & 3 & & & \\
\hline calreticulin & P27797 & 136 & 2 & & & \\
\hline endoplasmic reticulum protein 29 & P30040 & 101 & 3 & & & \\
\hline peroxiredoxin 3 & P30048 & 84 & 2 & & & \\
\hline protein disulfide isomerase family a, member 3 (erp57) & P30101 & 139 & 4 & & & \\
\hline aldehyde dehydrogenase 1 family, member b1 & P30837 & 120 & 2 & & & \\
\hline heterogeneous nuclear ribonucleoprotein h1 & P31943 & 99 & 2 & & & \\
\hline prohibitin & P35232 & 203 & 3 & & & \\
\hline heat shock $70 \mathrm{kDa}$ protein 9b (mortalin-2) & P38646 & 181 & 2 & & & \\
\hline tu translation elongation factor, mitochondrial & P49411 & 65 & 2 & & & \\
\hline proteasome (prosome, macropain) subunit, beta type, 3 & P49720 & 76 & 2 & & & \\
\hline isocitrate dehydrogenase $3(\mathrm{nad}+)$ alpha & P50213 & 88 & 2 & & & \\
\hline actin, beta & P60709 & 76 & 2 & & & \\
\hline arp1 actin-related protein 1 homolog a, centractin alpha & P61163 & 148 & 3 & & & \\
\hline $\begin{array}{l}\text { guanine nucleotide binding protein (g protein), beta } \\
\text { polypeptide } 2\end{array}$ & P62879 & 140 & 2 & & & \\
\hline TNF receptor-associated protein 1 & Q12931 & 120 & 2 & & & \\
\hline septin 2 & Q15019 & 219 & 4 & & & \\
\hline inner membrane protein, mitochondrial (mitofilin) & Q16891 & 158 & 4 & & & \\
\hline translocase of inner mitochondrial membrane 50 homolog & Q3ZCQ8 & 127 & 3 & & & \\
\hline eukaryotic translation elongation factor 1 gamma & Q53YD7 & 109 & 3 & & & \\
\hline chaperonin containing tcp1, subunit 6a (zeta 1) & Q59ET3 & 137 & 3 & & & \\
\hline $\begin{array}{l}\text { stress-induced-phosphoprotein } 1 \text { (hsp70/hsp90-organizing } \\
\text { protein) }\end{array}$ & Q5TZU9 & 142 & 3 & & & \\
\hline dead (asp-glu-ala-asp) box polypeptide 48 (elF4A) & Q6IBQ2 & 108 & 2 & & & \\
\hline family with sequence similarity 82 , member $b$ & Q96DB5 & 80 & 2 & & & \\
\hline
\end{tabular}

of levels associated with each of the treatment conditions suggests they are co-regulated upon IFN treatment and/or virus infection, as described below and as illustrated in Figure 2.

A search with the GO term Biological Process returned 17 annotations $(\mathrm{P}<0.01$, Fisher's exact), segregated into two annotation clusters. Annotation cluster 1 included proteins with defined roles in apoptosis. Several showed increases or decreases when cells were treated with IFN, yet all showed decreased levels of expression upon virus infection compared to mock infected controls (Figure 2). Most showed trends towards increased levels when cells were pre-treated with IFN prior to infection. Five of the eight proteins with decreased levels of expression in OSU infected cells as compared to mock infected controls were classified as negative regulators of apoptosis, including HSP27, mortalin, GRP94, GRP78, peroxiredoxin 3, and Erp57, and are induced in response to cell stress.
GRP78 was identified as down-regulated in OSU infected cells compared to mock infected controls in the proteomic analysis, and confirmed by immunoblot (Figure 3A). GRP78 is noted here because of previous data that demonstrate GRP78 is up-regulated in cells infected with rotavirus strain RRV, suggesting a potential difference in modulation of cellular responses between these two virus strains [17]. This difference was further confirmed by immunoblot (Figure 3B) showing a decreased amount of GRP78 in OSU infected cells compared to RRV infected cells or cells infected with bovine strain NCDV. Potential mechanisms explaining this difference are not currently understood but clearly reflect different host cell interactions that are dependent on virus strain. GRP94 also has been reported to be up-regulated in RRV infected cells [17], in contrast to the data reported here in OSU infected cells. GRP94 was up-regulated by IFN treatment, and GRP78 showed a trend toward increased levels, but was determined to be not significant. 


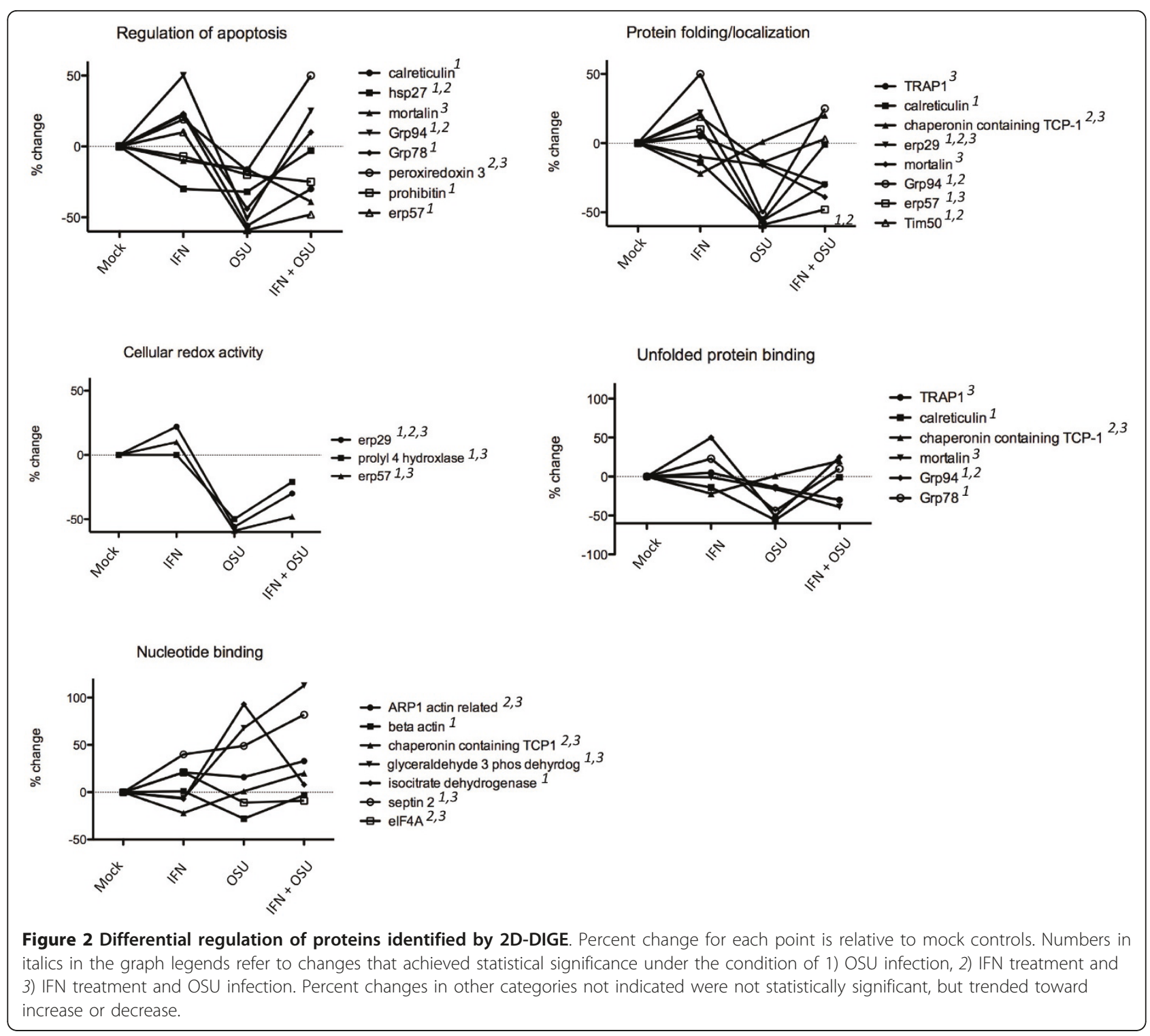

GO Biological Process Annotation cluster 2 included proteins with roles in protein folding and localization (Figure 2). All but one of these proteins (chaperonin containing protein TCP-1) localize to the ER or to mitochondria. As before, protein levels either increased or decreased upon IFN treatment, with all but one (Erp29) decreased during virus infection. Many of these proteins function as molecular chaperones that generally are upregulated in response to cell stress. The observation of decreased levels in OSU infected cells was somewhat surprising, but nonetheless consistent with a potential mechanism to down regulate the stress response that occurs non-specifically after viral infection.

GO Molecular Function returned 17 annotations $(\mathrm{P}<$ $0.05)$ and two annotation clusters. The first was associated with protein disulfide isomerase activity which functions in the oxidative environment of the ER to assist in disulfide bond formation and consequent protein folding. Erp29 and Erp57 were increased upon IFN treatment, but significantly down-regulated during virus infection. The second annotation cluster included proteins with roles in unfolded protein binding and nucleotide binding. Those involved in unfolded protein binding localize primarily to the ER and the mitochondria. As before, the levels of most of these proteins were decreased in OSU infected cells. In contrast to the results observed for proteins with roles in regulation of apoptosis, protein folding and localization, and unfolded protein binding, most of the proteins identified with functions that include nucleotide binding were increased upon OSU infection. The levels of these proteins, with the exception of $\beta$-actin, remained higher when cells were pre-treated with IFN. 


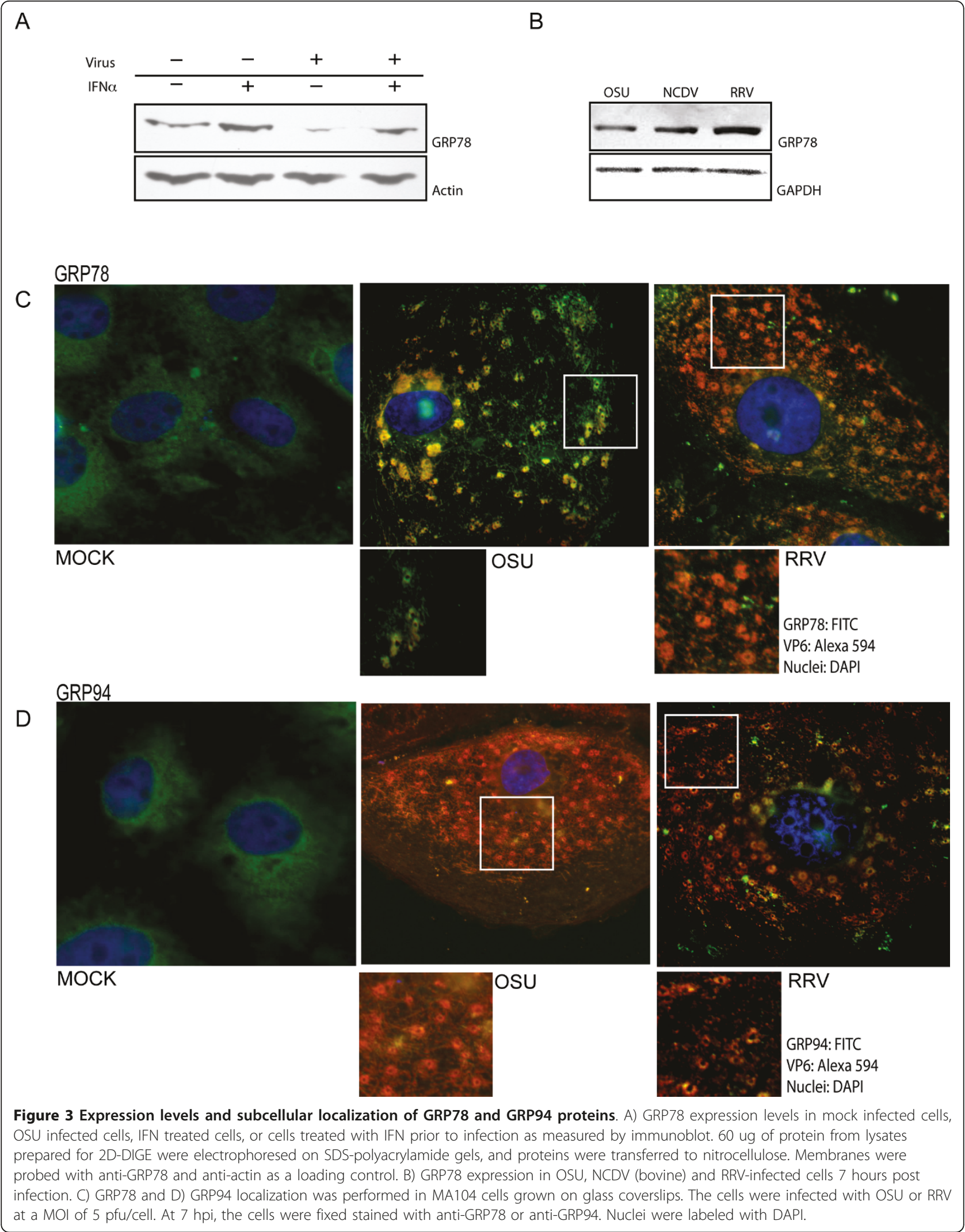




\section{Chaperones GRP78 and GRP94 localize to viroplasm patterns in infected cells}

Apparent decreases in cell stress proteins and proteins associated with ER chaperone functions led us to further examine these pathways in rotavirus infected cells. Chaperones are responsible for correctly folding nascent proteins in the ER lumen prior to their translocation to appropriate subcellular locations. It has been suggested that GRP78, GRP94 or both, are involved in the morphogenesis of rotavirus [17]. More recently it was suggested that GRP94 protein may not be essential for virus replication, while GRP78 protein plays an active role in quality control in the assembly of mature rotavirus particles [18]. Both GRP78 and GRP94 were identified in the current study as differentially regulated by OSU infection, and thus we evaluated the subcellular localization of these proteins in infected cells. MA104 cells were infected with rotavirus strains OSU or RRV, and their localization was determined by immunofluorescence. In mock infected cells, GRP78 and GRP94 showed reticular and perinuclear staining, consistent with an ER distribution (Figures 3C and 3D). Changes in the distribution of GRP78 and GRP94 were observed in cells infected with either OSU or RRV. Both were redirected to the pattern of viroplasms, overlapping the staining pattern of viral protein VP6. These results are consistent with previous reports indicating that GRP94, as well as other chaperone proteins such as PDI (protein disulfide isomerase) and calreticulin changed their distribution in rotavirus infected cells to a pattern similar to viroplasms, but calnexin, another ER chaperone, did not [18]. We also found similar changes in the localization of proteins Erp57, PDI and calreticulin in infected cells; however, we also observed redistribution of calnexin protein in a similar pattern to that observed for the other chaperones (data not shown).

\section{Proteins of the UPR redistribute to viroplasms in infected cells}

Activation of the UPR results in increased expression of chaperones due to the activation of ER stress sensors ATF6 (activating transcription factor 6 [30,31], IRE1 (inositol requiring endonuclease 1) [32-34] and PERK (PKR-like ER kinase) [35,36]. The UPR sensors are transmembrane proteins with the lumenal domains bound to GRP78 [37]. Accumulation of unfolded proteins in the ER causes GRP78 to dissociate from the sensor proteins, leading to phosphorylation of IRE1 and PERK. ATF6 translocates to the Golgi where it is cleaved, and the transcriptionally active fragment is transported to the nucleus to bind promoters containing ER stress response elements [31,37].

The subcellular localization of ATF6 and thus activation of the UPR was determined in OSU and RRV infected MA104 cells seven hours post-infection. ATF6 localized to the ER in mock infected cells, and to the nucleus in cells treated with 2DG, which is known to activate the UPR [38] (Figure 4A). In contrast, ATF6 localization was similar to the staining pattern of VP6 in infected cells, suggesting that translocation to the nucleus was blocked. Likewise, phosphorylation of PERK (p-PERK) was evaluated by immunofluorescence under the same conditions. p-PERK was not detected in mock infected cells as expected. In infected cells, p-PERK was observed surrounded by VP6 in a pattern distinct from that of ATF6, GRP78 and GRP94 (Figure 4B).

A time course of infection was performed to determine at which stage of rotavirus replication the observed changes in the localization of p-PERK occurred (Figure 4C). p-PERK was detected in a reticular location very close to the nuclei at one hpi in cells infected with either OSU or RRV. At two hpi, VP6 began to accumulate in the cytoplasm while p-PERK persisted in the ER. However, at three hpi, p-PERK was observed in the viroplasm pattern, and continued to accumulate here between four and five hpi. These results suggest PERK is activated during the initial stages of rotavirus infection, but like ATF6, is redistributed to viroplasms, although as indicated above, in a distinctive pattern to suggest inclusion within viroplasms.

Phosphorylation of IRE1 leads to splicing of XBP1 mRNA [34]. Translation of spliced XBP1 mRNA leads to synthesis of XBP1 protein that subsequently translocates to the nucleus to bind promoters containing ER stress response elements [39]. Although we could not detect phosphorylated IRE1 by immunostaining, RTPCR for XBP-1 mRNA revealed the presence of both the spliced and unspliced form, suggesting that IRE1 was activated (Figure 5D). Similar to the distribution of chaperones and ATF6 in infected cells, XBP1 staining was consistent with the staining pattern of viroplasms, and its nuclear translocation thus was blocked (data not shown). Localization of UPR effectors CHOP and GADD34 that are induced by activation of the UPR also was similar to the pattern of viroplasms. These proteins are not expressed in mock-infected cells, suggesting that rotavirus infection induces expression of these proteins (Figures 5A, B).

\section{Discussion}

We performed a small-scale proteomic analysis of cells infected with the OSU strain of rotavirus, cells treated with IFN, and cells treated with IFN prior to infection. The data described reflect differences in OSU-modulated, IFN-modulated and IFN pre-treatment-modulated proteins as compared to the mock controls. In general, trends were observed where identified proteins that increased upon IFN treatment were decreased in OSU infected cells. When cells were treated with IFN prior to 
A

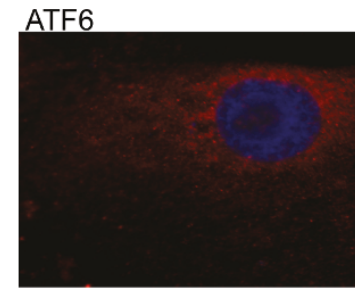

Mock

B

p-PERK

\section{p-PERK - OSU}

c
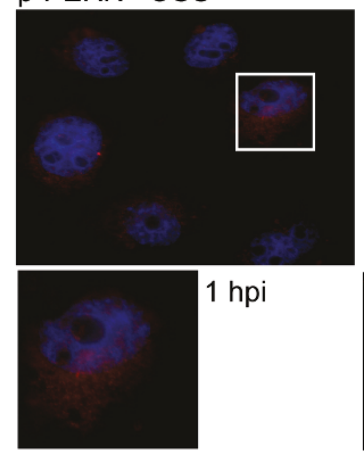

$1 \mathrm{hpi}$
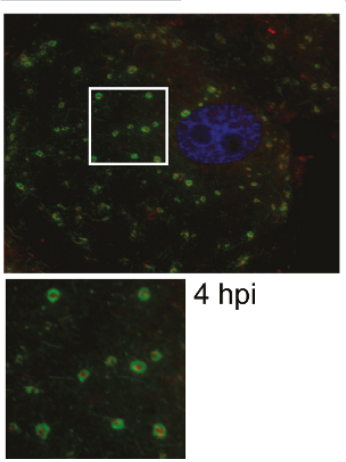
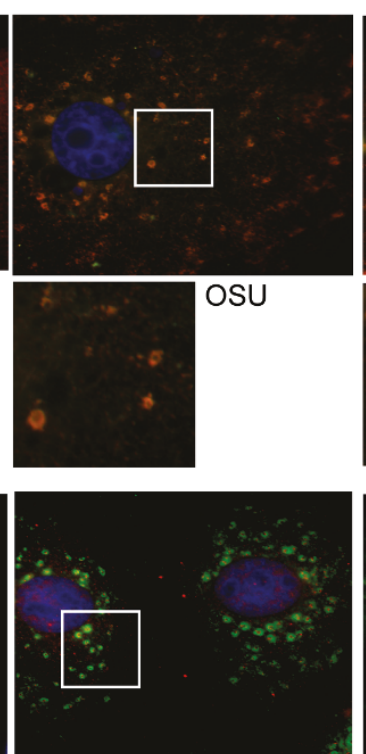

OSU
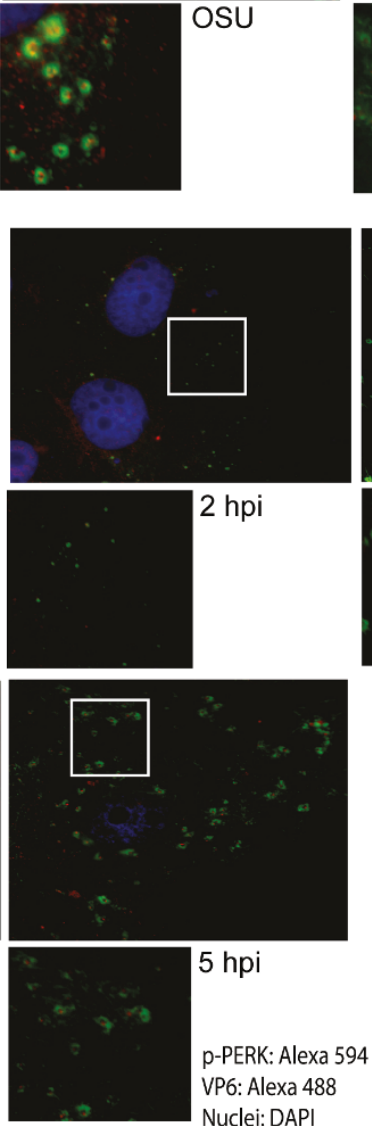
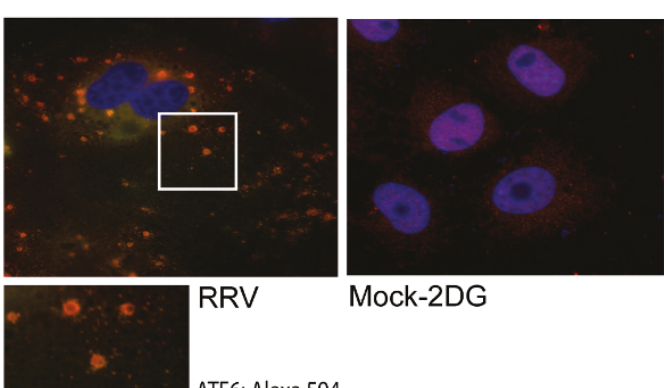

Mock-2DG

ATF6: Alexa 594

VP6: Alexa 488

Nuclei: DAPI
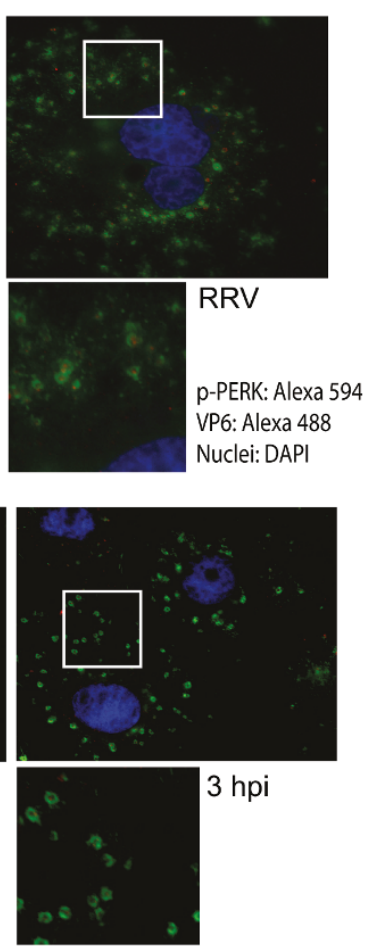

Figure 4 Subcellular localization of UPR sensor proteins ATF6 and p-PERK. MA104 cells were grown on glass coverslips and then infected with OSU or RRV at a MOI of five pfu/cell for seven hours. Mock infected cells treated with 2DG served as a positive control for UPR activation. A) ATF6 and B) p-PERK were stained with specific antibodies, followed by indicated Alexa-conjugated secondary antibodies. C) Epifluorescence microscopy of p-PERK expression over time during OSU infection (1-5 hpi) in MA104 cells. 


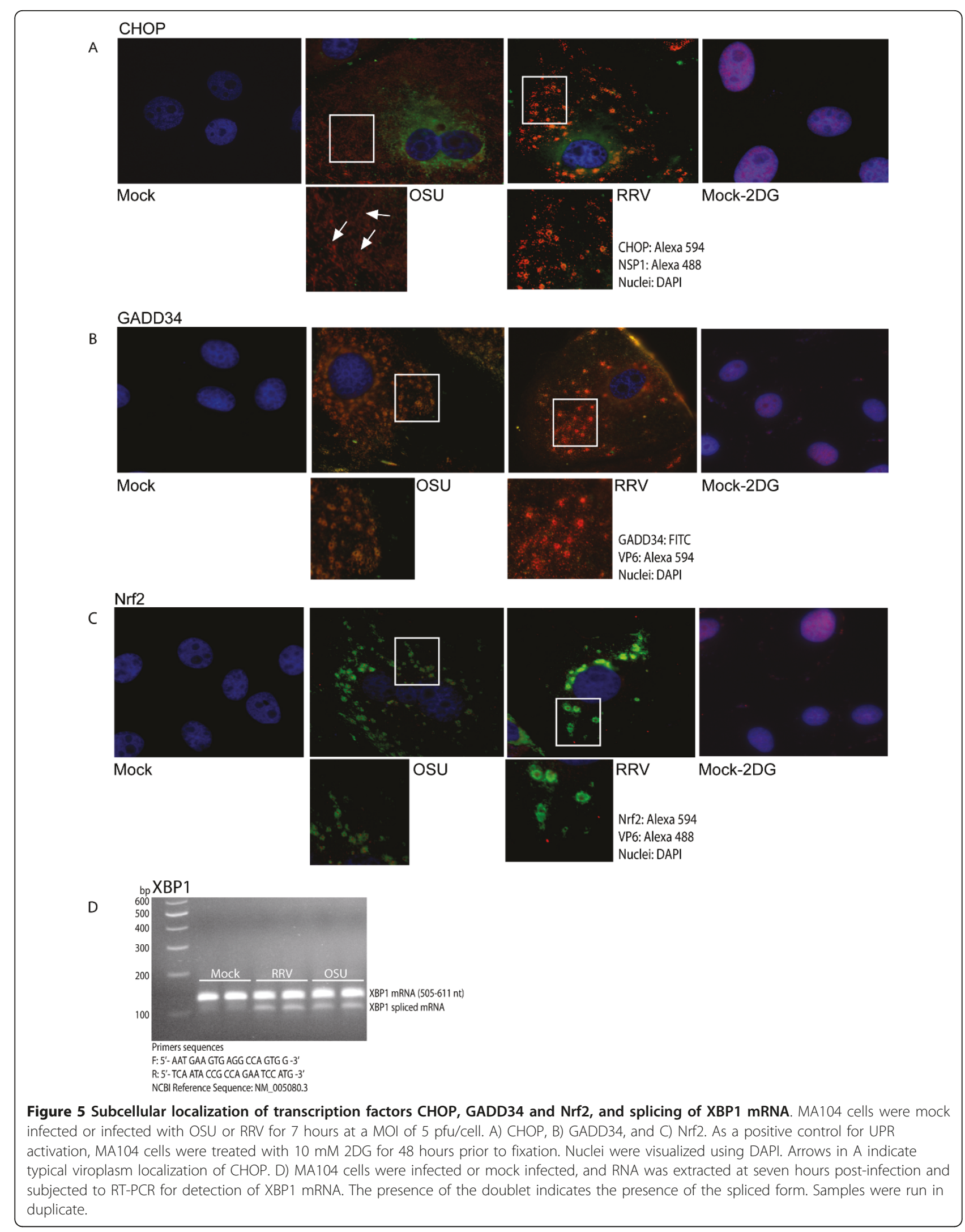


infection, most proteins returned to basal levels and not to levels induced by IFN alone, suggesting some effect of virus replication on these proteins. More detailed analyses are needed to determine whether the proteins induced by IFN and then apparently controlled by OSU infection are truly part of a specific antiviral response.

While identification of stress response pathways is common in proteomics studies, proteins expected to increase were instead decreased upon OSU infection. This in contrast to what has been reported previously for rotavirus by others, likely explained by the differences in the rotavirus strains used for analysis. That there are differences in the basic virus-host cell interactions between rotavirus strains is illustrated by differences in the way they affect the host innate immune response. For example, RRV infection results in proteasome-dependent degradation of interferon regulatory factors 3, 5, and 7 [22,23], yet IRF3 is stable in OSU infected cells [21]. Thus it is conceivable that other strain-specific host cell interactions that occur that could be reflected in different cellular responses.

Several studies of rotavirus cellular pathogenesis have focused on perturbations of calcium homeostasis $[10,40-44]$ and on alterations of cytoskeleton components [45-51], while others have investigated non-classic cellular mechanisms for viral protein transport $[12,52,53]$. Fewer studies exist on the impact of rotavirus infection on cell stress response pathways, and how rotavirus could modulate these pathways to attenuate innate defense mechanisms [21-23,54], including the ER-initiated UPR [18]. The ER plays a fundamental role in the morphogenesis of new rotavirus particles, as it is where final maturation of the particles occurs. ER calcium pools are reduced during rotavirus infection and cellular protein synthesis is redirected to favor viral protein synthesis $[42,43]$. Therefore, it is reasonable to predict that rotavirus infection leads to UPR activation. In this study, activation of the UPR sensors was demonstrated by detection of p-PERK, splicing of XBP1 mRNA suggesting IRE1 phosphorylation, and the redistribution of ATF6. In addition, expression of downstream effectors CHOP, GADD34 and Nrf2 (Figure 5C) also was detected. CHOP (GADD153) is a bZIP containing transcription factor, induced by ER stress, and over-expression of CHOP promotes apoptosis [55]. Like CHOP protein, GADD34 is expressed only under ER stress when PERK is phosphorylated [56]. Nrf2 is phosphorylated by PERK and translocates to the nucleus to activate transcription of antioxidant elements [57].

Phosphorylation of PERK leads to phosphorylation of translation initiation factor eIF2 $\alpha[35,58,59]$ and it has been reported that eIF2 $\alpha$ is phosphorylated in rotavirus infected cells by PKR [60]. These events trigger synthesis of transcription factor ATF4 that drives transcription of stress proteins Nrf2, GADD34 and CHOP, and the over-expression of chaperones including GRP78 [58]. We observed that Nrf2, GADD34, and CHOP are expressed in infected cells. However, the subcellular localization of these proteins was associated with viroplasm patterns and co-localized with VP6. All these proteins were surrounding the viroplasms, with the exception of Nrf2 that like p-PERK, appeared localized within viroplasms. In the early stages of infection with OSU or RRV (up to 2 hpi) p-PERK displayed an ERcytoplasmic localization. At $3 \mathrm{hpi}$, p-PERK was observed surrounded by VP6, which increased further between 5 and 7 hpi. These results strongly suggest that in the early stages of rotavirus infection the PERK-dependent UPR pathway is efficiently activated. As the infection progresses, $\mathrm{p}$-PERK is redirected to the viroplasms and sequestered into these viral structures, potentially avoiding amplification of the UPR. Inhibition of nuclear translocation of CHOP and GADD34, in addition to other UPR proteins, may serve to avoid the activation of cellular pro-apoptotic mechanisms. In a manner similar to initial activation of the UPR followed by down-regulation, Halasz et al. [61] reported activation of apoptosis in early stages of rotavirus infection in MA104 and HT29 cells, yet at six hours post-infection, markers of apoptosis including Annexin V and 7-AAD were absent. Our results show that pro-apoptotic transcription factors are expressed in early stages of rotavirus infection and then are directed or sequestered around or within viroplasms. Together, the data strongly suggest a loss of control of key metabolic pathways of signaling for an effective response against infection, and that viroplasms may play a role, directly or indirectly modulating cellular defense mechanisms.

As mentioned above, the phosphorylation of IRE1 leads the splicing of XBP1 mRNA, resulting in translation of XBP1. IRE1 phosphorylation also activates the cellular pathway of autophagy [62]. Like PERK-dependent stress proteins, XBP1 translocation to the nucleus was blocked and redistributed to viroplasms. We did not evaluate components of the autophagy pathway, however, it has been reported that LC3 a cellular marker of autophagy interacts with NSP4-EGFP [63]. Splicing of XBP1 mRNA and possible activation of autophagy suggests that like PERK, IRE1 is activated and sequestered by viroplasms at seven hpi.

Transcriptionally active ATF6 promotes expression of ER lumenal chaperones as well as CHOP and XBP1. The results shown in this study indicate that in a way similar to the other UPR sensors, ATF6 translocation to the nucleus is blocked at later times post infection, and instead colocalizes with VP6, again potentially affecting the efficiency of ATF6-dependent effector mechanisms. Repeated observations on the localization of the UPR 


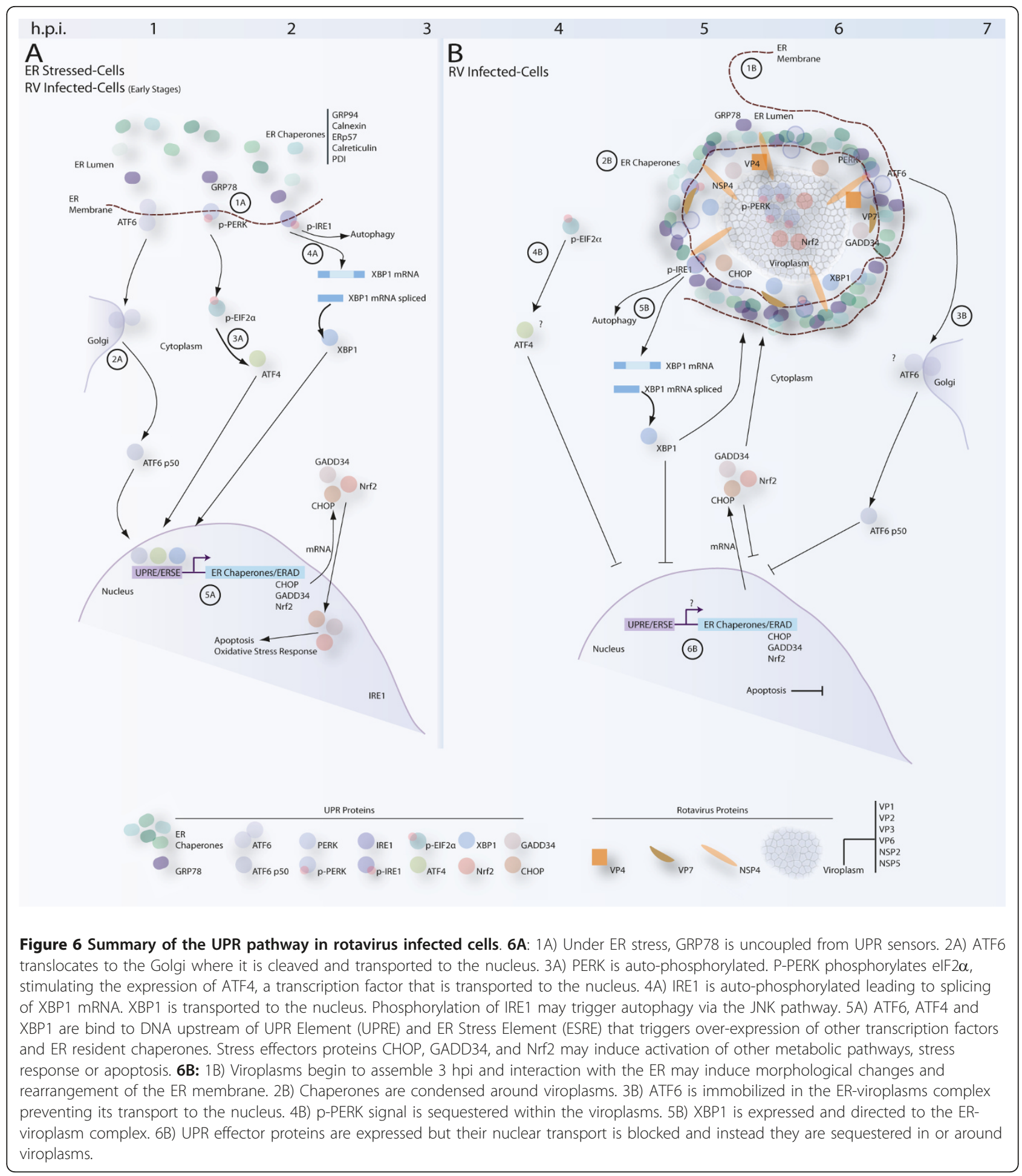

proteins to follow the pattern of viroplasms may suggest that these viral inclusions may function not only in the morphogenesis of new virus particles, but also may play a central role in the evasion of cellular mechanisms that affect virus replication. This idea is further supported by previous observations that the p65 subunit of $\mathrm{NF} \kappa \mathrm{B}$ also localizes with viroplasms in OSU infected cells. Inhibition of nuclear translocation could be explained by the disorganization of the cytoskeleton reported during rotavirus infection. However, in cells infected with OSU, where translocation of p65 is inhibited, IRF3 accumulates in the nucleus, suggesting some selectivity to the 
inhibition process. Clearly the mechanisms by which rotavirus infection and the viral proteins involved in disrupting nuclear import of critical transcription factors need further exploration.

Changes in the distribution of the UPR proteins observed in this study may be due to morphological changes that the ER must overcome during rotavirus infection rather than due to an activity modulated by viral infection. Electron microscopy studies have suggested that the ER cisternae envelop the viroplasms, providing one possible explanation for changes in the location of UPR proteins [53,64]. Redistribution of the UPR proteins may contribute to the recruitment of chaperones that are necessary for viral protein folding and particle assembly. The mechanism by which some cellular proteins become localized to viroplasms is not clear, and the interaction between viroplasms and ER membranes is not well defined. A summary of the activity of the UPR in rotavirus infected cells is provided in Figure 6.

We have shown by 2D-DIGE that several proteins associated with cell stress are decreased in OSU infected cells, and follow up studies indicate their subcellular redistribution in cells infected with either OSU or RRV. Together, the data indicate that the stress response, particularly the UPR is activated upon infection, but is prevented from amplifying by inhibition of nuclear translocation of key transcription factors, effector proteins, and redistributed chaperones. Further investigations are ongoing to ascertain a mechanism for sequestration of these proteins with viroplasms.

\footnotetext{
Acknowledgements

This work was supported by USDA/NRICGP grant 02657 to MEH. Additional support was provided by NCRR RR020185 and the Montana Agriculture Experiment Station. We extend appreciation to Mark Shaneyfelt for excellent technical support.
}

\section{Author details \\ ${ }^{1}$ Immunology and Infectious Diseases, Montana State University, Bozeman MT, 59718, USA. ${ }^{2}$ Chemistry and Biochemistry, Montana State University, Bozeman MT, 59717, USA.}

\section{Authors' contributions}

$J L Z$ designed UPR experiments, performed microscopy and wrote the manuscript. KE assisted in the proteomics studies, participated in experimental design and contributed to writing the manuscript. WSM assisted in the design, interpretation and performance of the proteomics experiments. NRF participated in experimental design, data interpretation, and performed RT-PCR. BB assisted in design and interpretation of the proteomics work. MEH conceived of the basic research premise, participated in experimental design and data interpretation, and assisted in writing the manuscript. All authors read and approved the final manuscript.

\section{Competing interests}

The authors declare that they have no competing interests.

Received: 22 April 2011 Accepted: 20 July 2011 Published: 20 July 2011
References

1. Tate JE, Patel MM, Steele AD, Gentsch JR, Payne DC, Cortese MM, Nakagomi O, Cunliffe NA, Jiang B, Neuzil KM, et al: Global impact of rotavirus vaccines. Expert Rev Vaccines 9:395-407.

2. Fabbretti E, Afrikanova I, Vascotto F, Burrone OR: Two non-structural rotavirus proteins, NSP2 and NSP5, form viroplasm-like structures in vivo. J Gen Virol 1999, 80(Pt 2):333-339.

3. Silvestri LS, Taraporewala ZF, Patton JT: Rotavirus replication: plus-sense templates for double-stranded RNA synthesis are made in viroplasms. Virol 2004, 78:7763-7774.

4. Patton JT, Silvestri LS, Tortorici MA, Vasquez-Del Carpio R, Taraporewala ZF: Rotavirus genome replication and morphogenesis: role of the viroplasm. Curr Top Microbiol Immunol 2006, 309:169-187.

5. Lopez T, Rojas M, Ayala-Breton C, Lopez S, Arias CF: Reduced expression of the rotavirus NSP5 gene has a pleiotropic effect on virus replication. $J$ Gen Virol 2005, 86:1609-1617.

6. Contin R, Arnoldi F, Campagna M, Burrone OR: Rotavirus NSP5 orchestrates recruitment of viroplasmic proteins. J Gen Virol 91:1782-1793.

7. Campagna M, Eichwald C, Vascotto F, Burrone OR: RNA interference of rotavirus segment 11 mRNA reveals the essential role of NSP5 in the virus replicative cycle. J Gen Virol 2005, 86:1481-1487.

8. Au KS, Chan WK, Burns JW, Estes MK: Receptor activity of rotavirus nonstructural glycoprotein NS28. J Virol 1989, 63:4553-4562.

9. Meyer JC, Bergmann CC, Bellamy AR: Interaction of rotavirus cores with the nonstructural glycoprotein NS28. Virology 1989, 171:98-107.

10. Michelangeli F, Liprandi F, Chemello ME, Ciarlet M, Ruiz MC: Selective depletion of stored calcium by thapsigargin blocks rotavirus maturation but not the cytopathic effect. J Virol 1995, 69:3838-3847.

11. Ahmadian S, Shahrabadi MS: Morphological study of the role of calcium in the assembly of the rotavirus outer capsid protein VP7. Biotech Histochem 1999, 74:266-273.

12. Jourdan N, Maurice M, Delautier D, Quero AM, Servin AL, Trugnan G: Rotavirus is released from the apical surface of cultured human intestinal cells through nonconventional vesicular transport that bypasses the Golgi apparatus. J Virol 1997, 71:8268-8278.

13. Cuadras MA, Feigelstock DA, An S, Greenberg HB: Gene expression pattern in Caco-2 cells following rotavirus infection. J Virol 2002, 76:4467-4482.

14. Rollo EE, Kumar KP, Reich NC, Cohen J, Angel J, Greenberg HB, Sheth R, Anderson J, Oh B, Hempson SJ, et al: The epithelial cell response to rotavirus infection. J Immunol 1999, 163:4442-4452.

15. Casola A, Estes MK, Crawford SE, Ogra PL, Ernst PB, Garofalo RP, Crowe SE: Rotavirus infection of cultured intestinal epithelial cells induces secretion of CXC and CC chemokines. Gastroenterology 1998, 114:947-955.

16. Casola A, Garofalo RP, Crawford SE, Estes MK, Mercurio F, Crowe SE, Brasier AR: Interleukin-8 gene regulation in intestinal epithelial cells infected with rotavirus: role of viral-induced IkappaB kinase activation. Virology 2002, 298:8-19.

17. Xu A, Bellamy AR, Taylor JA: BiP (GRP78) and endoplasmin (GRP94) are induced following rotavirus infection and bind transiently to an endoplasmic reticulum-localized virion component. J Virol 1998, 72:9865-9872.

18. Maruri-Avidal L, Lopez S, Arias CF: Endoplasmic reticulum chaperones are involved in the morphogenesis of rotavirus infectious particles. J Virol 2008, 82:5368-5380.

19. Graff JW, Mitzel DN, Weisend CM, Flenniken ML, Hardy ME: Interferon regulatory factor 3 is a cellular partner of rotavirus NSP1. J Virol 2002, 76:9545-9550.

20. Graff JW, Ewen J, Ettayebi K, Hardy ME: Zinc-binding domain of rotavirus NSP1 is required for proteasome-dependent degradation of IRF3 and autoregulatory NSP1 stability. J Gen Virol 2007, 88:613-620.

21. Graff JW, Ettayebi K, Hardy ME: Rotavirus NSP1 inhibits NFkappaB activation by inducing proteasome-dependent degradation of betaTrCP: a novel mechanism of IFN antagonism. PLoS Pathog 2009, 5 e1000280.

22. Barro M, Patton JT: Rotavirus nonstructural protein 1 subverts innate immune response by inducing degradation of IFN regulatory factor 3. Proc Natl Acad Sci USA 2005, 102:4114-4119.

23. Barro M, Patton JT: Rotavirus NSP1 inhibits expression of type I interferon by antagonizing the function of interferon regulatory factors IRF3, IRF5, and IRF7. J Virol 2007, 81:4473-4481. 
24. Holloway G, Truong TT, Coulson BS: Rotavirus antagonizes cellular antiviral responses by inhibiting the nuclear accumulation of STAT1, STAT2, and NF-kappaB. J Virol 2009, 83:4942-4951.

25. Credle JJ, Finer-Moore JS, Papa FR, Stroud RM, Walter P: On the mechanism of sensing unfolded protein in the endoplasmic reticulum. Proc Natl Acad Sci USA 2005, 102:18773-18784

26. Merksamer PI, Papa FR: The UPR and cell fate at a glance. J Cell Sci 123:1003-1006.

27. Maaty WS, Wiedenheft B, Tarlykov P, Schaff N, Heinemann J, Robison-Cox J, Valenzuela J, Dougherty A, Blum P, Lawrence CM, et al: Something old, something new, something borrowed; how the thermoacidophilic archaeon Sulfolobus solfataricus responds to oxidative stress. PLOS One 2009, 4:e6964.

28. Huang da W, Sherman BT, Lempicki RA: Systematic and integrative analysis of large gene lists using DAVID bioinformatics resources. Nat Protoc 2009, 4:44-57.

29. Gaddameedhi S, Chatterjee S: Association between the unfolded protein response, induced by 2-deoxyglucose, and hypersensitivity to cisplatin: a mechanistic study employing molecular genomics. J Cancer Res Ther 2009, 5(Suppl 1):S61-66.

30. Haze K, Yoshida H, Yanagi H, Yura T, Mori K: Mammalian transcription factor ATF6 is synthesized as a transmembrane protein and activated by proteolysis in response to endoplasmic reticulum stress. Mol Biol Cell 1999, 10:3787-3799.

31. Shen J, Chen X, Hendershot L, Prywes R: ER stress regulation of ATF6 localization by dissociation of BiP/GRP78 binding and unmasking of Golgi localization signals. Dev Cell 2002, 3:99-111.

32. Shamu CE, Walter P: Oligomerization and phosphorylation of the Ire1p kinase during intracellular signaling from the endoplasmic reticulum to the nucleus. EMBO J 1996, 15:3028-3039.

33. Okamura K, Kimata Y, Higashio H, Tsuru A, Kohno K: Dissociation of Kar2p/ $\mathrm{BiP}$ from an ER sensory molecule, Ire1p, triggers the unfolded protein response in yeast. Biochem Biophys Res Commun 2000, 279:445-450.

34. Calfon M, Zeng H, Urano F, Till JH, Hubbard SR, Harding HP, Clark SG, Ron D: IRE1 couples endoplasmic reticulum load to secretory capacity by processing the XBP-1 mRNA. Nature 2002, 415:92-96.

35. Harding HP, Zhang $Y$, Ron D: Protein translation and folding are coupled by an endoplasmic-reticulum-resident kinase. Nature 1999, 397:271-274.

36. Marciniak SJ, Garcia-Bonilla L, Hu J, Harding HP, Ron D: Activationdependent substrate recruitment by the eukaryotic translation initiation factor 2 kinase PERK. J Cell Biol 2006, 172:201-209.

37. Bertolotti A, Zhang Y, Hendershot LM, Harding HP, Ron D: Dynamic interaction of BiP and ER stress transducers in the unfolded-protein response. Nat Cell Biol 2000, 2:326-332.

38. Park HR, Tomida A, Sato S, Tsukumo Y, Yun J, Yamori T, Hayakawa Y, Tsuruo T, Shin-ya K: Effect on tumor cells of blocking survival response to glucose deprivation. J Nat/ Cancer Inst 2004, 96:1300-1310.

39. Lee AH, Iwakoshi NN, Glimcher LH: XBP-1 regulates a subset of endoplasmic reticulum resident chaperone genes in the unfolded protein response. Mol Cell Biol 2003, 23:7448-7459.

40. Michelangeli F, Ruiz MC, del Castillo JR, Ludert JE, Liprandi F: Effect of rotavirus infection on intracellular calcium homeostasis in cultured cells. Virology 1991, 181:520-527.

41. Berkova Z, Morris AP, Estes MK: Cytoplasmic calcium measurement in rotavirus enterotoxin-enhanced green fluorescent protein (NSP4-EGFP) expressing cells loaded with Fura-2. Cell Calcium 2003, 34:55-68.

42. Ruiz MC, Diaz Y, Pena F, Aristimuno OC, Chemello ME, Michelangeli F: Ca2+ permeability of the plasma membrane induced by rotavirus infection in cultured cells is inhibited by tunicamycin and brefeldin A. Virology 2005, 333:54-65.

43. Diaz Y, Chemello ME, Pena F, Aristimuno OC, Zambrano JL, Rojas H, Bartoli F, Salazar L, Chwetzoff S, Sapin C, et al: Expression of nonstructural rotavirus protein NSP4 mimics $\mathrm{Ca} 2+$ homeostasis changes induced by rotavirus infection in cultured cells. J Virol 2008, 82:11331-11343.

44. Zambrano JL, Diaz Y, Pena F, Vizzi E, Ruiz MC, Michelangeli F, Liprandi F, Ludert JE: Silencing of rotavirus NSP4 or VP7 expression reduces alterations in $\mathrm{Ca} 2+$ homeostasis induced by infection of cultured cells. J Virol 2008, 82:5815-5824.

45. Nejmeddine M, Trugnan G, Sapin C, Kohli E, Svensson L, Lopez S, Cohen J: Rotavirus spike protein VP4 is present at the plasma membrane and is associated with microtubules in infected cells. J Virol 2000, 74:3313-3320.
46. Brunet JP, Jourdan N, Cotte-Laffitte J, Linxe C, Geniteau-Legendre M, Servin A, Quero AM: Rotavirus infection induces cytoskeleton disorganization in human intestinal epithelial cells: implication of an increase in intracellular calcium concentration. J Virol 2000, 74:10801-10806.

47. Xu A, Bellamy AR, Taylor JA: Immobilization of the early secretory pathway by a virus glycoprotein that binds to microtubules. EMBO J 2000, 19:6465-6474.

48. Cabral-Romero C, Padilla-Noriega L: Association of rotavirus viroplasms with microtubules through NSP2 and NSP5. Mem Inst Oswaldo Cruz 2006, 101:603-611.

49. Berkova Z, Crawford SE, Blutt SE, Morris AP, Estes MK: Expression of rotavirus NSP4 alters the actin network organization through the actin remodeling protein cofilin. J Virol 2007, 81:3545-3553.

50. Gardet A, Breton M, Trugnan G, Chwetzoff S: Role for actin in the polarized release of rotavirus. J Virol 2007, 81:4892-4894.

51. Martin D, Duarte M, Lepault J, Poncet D: Sequestration of free tubulin molecules by the viral protein NSP2 induces microtubule depolymerization during rotavirus infection. J Virol 84:2522-2532.

52. Cuadras MA, Greenberg HB: Rotavirus infectious particles use lipid rafts during replication for transport to the cell surface in vitro and in vivo. Virology 2003, 313:308-321.

53. Cuadras MA, Bordier BB, Zambrano JL, Ludert JE, Greenberg HB: Dissecting rotavirus particle-raft interaction with small interfering RNAs: insights into rotavirus transit through the secretory pathway. J Virol 2006, 80:3935-3946.

54. Sen A, Feng N, Ettayebi $K$, Hardy ME, Greenberg HB: IRF3 inhibition by rotavirus NSP1 is host cell and virus strain dependent but independent of NSP1 proteasomal degradation. J Virol 2009, 83:10322-10335.

55. McCullough KD, Martindale JL, Klotz LO, Aw TY, Holbrook NJ: Gadd153 sensitizes cells to endoplasmic reticulum stress by down-regulating $\mathrm{Bcl} 2$ and perturbing the cellular redox state. Mol Cell Biol 2001, 21:1249-1259.

56. Jousse C, Oyadomari S, Novoa I, Lu P, Zhang Y, Harding HP, Ron D: Inhibition of a constitutive translation initiation factor 2alpha phosphatase, CReP, promotes survival of stressed cells. J Cell Biol 2003, 163:767-775.

57. Nguyen T, Sherratt PJ, Pickett CB: Regulatory mechanisms controlling gene expression mediated by the antioxidant response element. Annu Rev Pharmacol Toxicol 2003, 43:233-260.

58. Harding HP, Novoa I, Zhang Y, Zeng H, Wek R, Schapira M, Ron D: Regulated translation initiation controls stress-induced gene expression in mammalian cells. Mol Cell 2000, 6:1099-1108.

59. Harding HP, Zhang Y, Bertolotti A, Zeng H, Ron D: Perk is essential for translational regulation and cell survival during the unfolded protein response. Mol Cell 2000, 5:897-904.

60. Rojas M, Arias CF, Lopez S: Protein kinase $R$ is responsible for the phosphorylation of elF2alpha in rotavirus infection. $J$ Virol 84:10457-10466.

61. Halasz P, Holloway G, Coulson BS: Death mechanisms in epithelial cells following rotavirus infection, exposure to inactivated rotavirus or genome transfection. J Gen Virol 91:2007-2018.

62. Ogata M, Hino S, Saito A, Morikawa K, Kondo S, Kanemoto S, Murakami T, Taniguchi M, Tanii I, Yoshinaga K, et al: Autophagy is activated for cell survival after endoplasmic reticulum stress. Mol Cell Biol 2006, 26:9220-9231.

63. Berkova Z, Crawford SE, Trugnan G, Yoshimori T, Morris AP, Estes MK: Rotavirus NSP4 induces a novel vesicular compartment regulated by calcium and associated with viroplasms. J Virol 2006, 80:6061-6071.

64. Lopez T, Camacho M, Zayas M, Najera R, Sanchez R, Arias CF, Lopez S: Silencing the morphogenesis of rotavirus. J Virol 2005, 79:184-192.

doi:10.1186/1743-422X-8-359

Cite this article as: Zambrano et al: Rotavirus infection activates the UPR but modulates its activity. Virology Journal 2011 8:359. 